\title{
Hydrogen diffusion through polymer membranes
}

\author{
Nicolas Gay ${ }^{1,}$, Takoua Lamouchi ${ }^{1}$, Franck Agostini ${ }^{1}$, Catherine A. Davy ${ }^{2}$, and Frédéric \\ Skoczylas ${ }^{1 *}$ \\ ${ }^{1}$ Univ Lille, CNRS, Centrale Lille, LamCube FRE 2016, F-59000, Lille, France \\ ${ }^{2}$ Univ Lille, CNRS, Centrale Lille, ENSCL, Univ Artois, UCCS UMR 8181, F-59000 Lille, France
}

\begin{abstract}
This experimental study determines $\mathrm{H}_{2}$ transfer properties of High Density PolyEthylene (HDPE) or epoxy membranes. Two different techniques are compared. The pressure gradient technique is analyzed for permeability or diffusion. Results show that the main phenomenon involved is diffusion. The second technique involves a gas concentration gradient. Although implying significantly slower kinetics, this classical technique is consistent with results obtained with the faster pressure gradient technique.
\end{abstract}

\section{Introduction}

Polymer membranes are used in the industry as watertight sealing barriers for low-level radioactive waste storage. They are generally made of High Density PolyEthylene (HDPE) or epoxy. Waste may contain metals (e.g. aluminum) or organic materials. The presence of water in contact with this waste, whether accidental or residual, may trigger gas-producing reactions, particularly hydrogen gas [1], and lead to explosion risks.

Although watertight, polymer membranes may allow gas transfer, first without significant gas pressure gradient $\Delta \mathrm{P}$, and, with time, under $\Delta \mathrm{P}$. In both instances, gas transfer properties of polymer membranes must be quantified to assess the $\mathrm{H}_{2}$ accumulation risk (or leakage rate) by coupling with numerical simulation codes.

For HDPE or epoxy, very few data are available in the literature, relating to transport of pure hydrogen under pressure or concentration gradients. Van Krevelen et al. [2] provide diffusion coefficients for pure HDPE or epoxy, but solely for $\mathrm{CO}_{2}, \mathrm{O}_{2}$ or $\mathrm{N}_{2}$ gases. Moreover, diffusion coefficients of polymers are obtained through very lengthy experiments, and they are dispersive in nature, depending on the actual polymer structure and/or filler minerals $[2,3]$.

In this research, we investigate both scenarii for $\mathrm{H}_{2}$ presence in contact with polymer membranes, by subjecting samples either to a concentration gradient, or to a pressure gradient of hydrogen. Two original experiments are designed, carefully calibrated and setup in the laboratory. First, a custom permeameter is operated at different concentrations and gas pressures. It allows to quantify gas flowrate and to analyze whether gas transfer is governed by permeation (convection) or by diffusion. Particular precautions are taken in

* Corresponding author: frederic.skoczylas@ centralelille.fr 
relation to handling hydrogen, which limit experimental possibilities mainly in terms of maximum gas pressure. Tests are also conducted with nitrogen gas, to investigate the effect of gas nature. Moreover, very low gas flowrates are measured. It is a research domain where our laboratory has wide experience, since we are able to measure gas permeabilities down to $10^{-22} \mathrm{~m}^{2}[4]$.

\section{Materials and methods}

HDPE membranes are made of a patented mix of pure HDPE and filler minerals of $2 \mathrm{~mm}$ thickness (Fig. 1a), and $0.97 \mathrm{~g} / \mathrm{cm}^{3}$ (+/- 0.02) density, provided by AGRU-Franck GmbH (Wölfersheim, Germany). This small thickness has imposed a specific design of the permeameter test bench, which is detailed hereafter. No information is provided by the manufacturer on their chemical composition, and on the filler nature potentially modifying its transport properties compared to pure HDPE [2]. Three membranes 1,2 and $3(10 \mathrm{~cm}$ diameter) are tested with the permeameter, and one membrane $\mathrm{n.} 4\left(17.5 \mathrm{x} 4.1 \mathrm{~cm}^{2}\right)$ with the classical diffusion test.

(a)

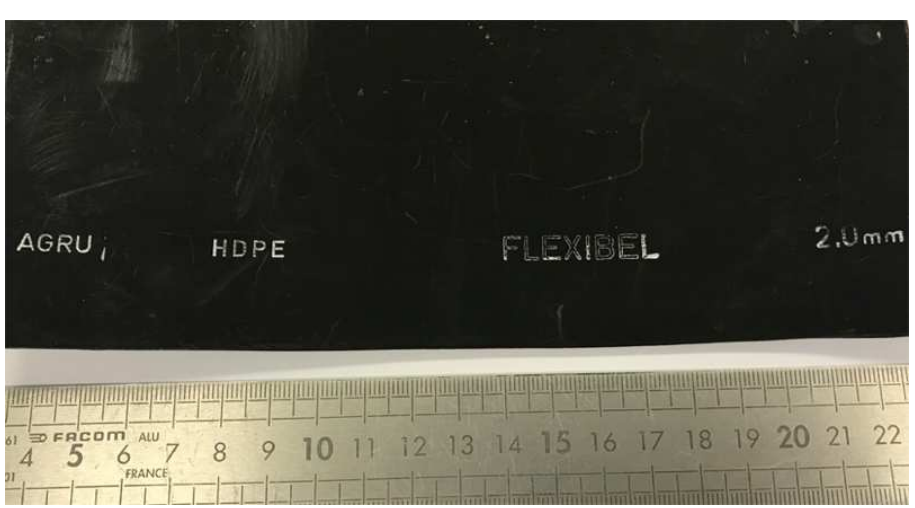

(b)

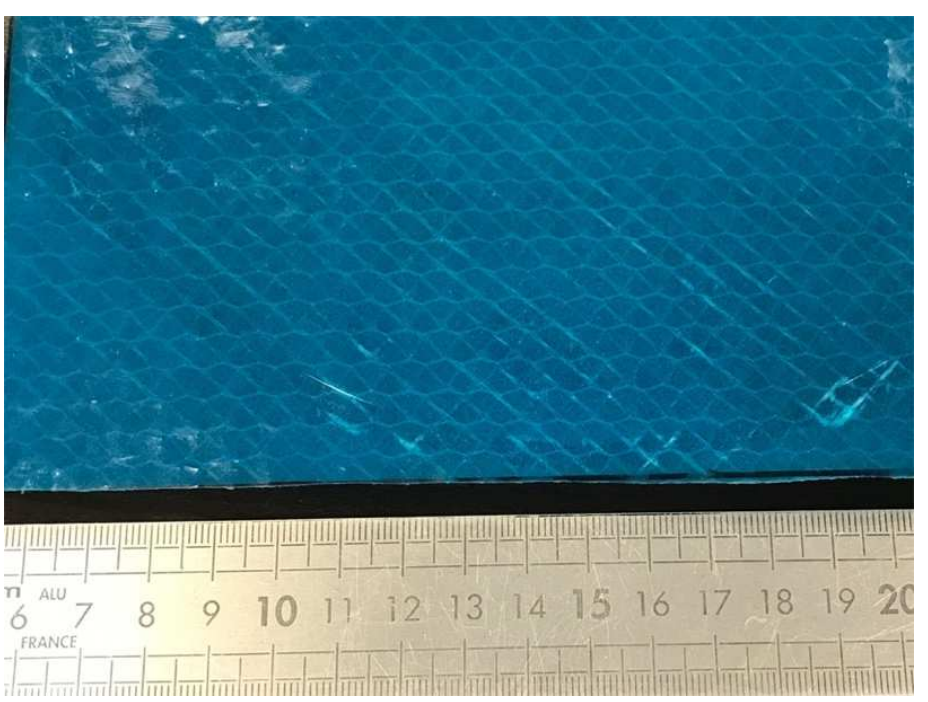

Fig. 1. (a): HDPE membrane and (b): epoxy membrane tested for hydrogen diffusion.

Patented epoxy resin membranes (Fig. 1b), reinforced with glass fibers, are also tested, with $1.25 \mathrm{~mm}$ thickness and $1.30 \mathrm{~g} / \mathrm{cm}^{3}(+/-0.02)$ density. 


\subsection{Pressure gradient technique}

This test set-up is designed to fit several constraints, namely 1) to use a wide exchange surface area between gas and polymer membrane to maximize gas flowrates, 2) to measure very low gas flowrates, and 3) at maximum gas pressure of $1.7 \mathrm{MPa}$. The flowrate measurement technique is deduced from small pressure variations in a chamber of small volume $\mathrm{V}_{\mathrm{r}}$, carefully calibrated and located after the membrane (downstream chamber) (Fig. 2). The lateral sealing of the system is ensured by a strong clamping of the upper and bottom set-up metal parts and by 4 O-ring joints. On the upstream membrane side, the injection pressure $P_{1}$ is kept constant, while on the downstream side, inside $V_{r}$, pressure increases from atmospheric pressure $\mathrm{P}_{2}$ by $\Delta \mathrm{P}$, of only a few hundreds of $\mathrm{Pa}$. This observation also eliminates a potential leakage scenario.

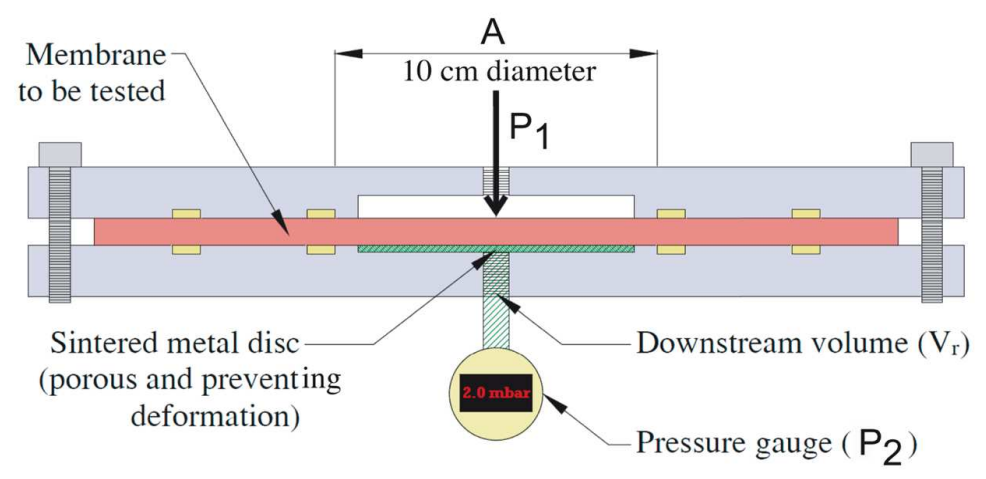

Fig. 2. 2D representation of the disk-shaped permeameter set-up, applying a pressure gradient $\left(\mathrm{P}_{1}-\right.$ $\mathrm{P}_{2}$ ) to the HDPE membrane (in red).

The main assumption is to analyze gas transfer as unidirectional, i.e. only through the exchange surface of area A, as indicated in Fig. 2, while neglecting any lateral parasitic flow (owing to sample clamping). Any volume change of reservoir $\mathrm{V}_{\mathrm{r}}$ is also neglected, thanks to a porous sintered disk placed after the membrane, which hinders polymer deformation.

Volume gas flowrate $\mathrm{Q}$ is estimated by measuring a slight increase in pressure $\Delta \mathrm{P}$ during time $\Delta \mathrm{t}$ in downstream reservoir $\mathrm{V}_{\mathrm{r}}$. The corresponding mass flowrate during $\Delta \mathrm{t}$ is $\mathrm{Q}_{\text {mass }}=$ $\mathrm{Q} \rho_{\text {mean }}=\Delta \mathrm{m} / \Delta \mathrm{t}=\left(\Delta \rho \mathrm{V}_{\mathrm{r}} / \Delta \mathrm{t}\right)$. The perfect gas law is then applied inside $\mathrm{V}_{\mathrm{r}}$, assumed at an average pressure $\mathrm{P}_{2}$ (with $\Delta \mathrm{P}<<\mathrm{P}_{2}$, on the first order, $\mathrm{P}_{2}+\Delta \mathrm{P} \approx \mathrm{P}_{2}$ ) and at constant temperature $\mathrm{T}$, so that the mean gas density $\rho_{\text {mean }}$ is equal to $\left(\Delta \rho \mathrm{P}_{2}\right) / \Delta \mathrm{P}$. Finally, $\mathrm{Q}$ is written as [4-9]:

$$
\mathrm{Q}=\frac{\mathrm{V}_{\mathrm{r}} \Delta \mathrm{P}}{\mathrm{P}_{2} \Delta \mathrm{\tau}}
$$

If this flowrate is due to permeation, Darcy's law applies and leads to the Hagen-Poiseuille law [4-9]:

$$
\mathrm{K}_{\mathrm{app}}=\frac{2 \mu \mathrm{QeP} \mathrm{P}_{2}}{\mathrm{~A}\left(\mathrm{P}_{1}^{2}-\mathrm{P}_{2}^{2}\right)}
$$

$\mathrm{K}_{\text {app }}$ is apparent gas permeability (in $\mathrm{m}^{2}$ ), $\mu$ is gas dynamic viscosity (in Pa.s), and e is membrane thickness.

The experiment is also analyzed by assuming that gas flow is solely due to diffusion, through an isotropic polymer medium. As downstream overpressure $\Delta \mathrm{P}$ is very low (a few 
hundreds of $\mathrm{Pa}$ ), on the first order, gas concentration gradient is assumed equal to c/e, where $\mathrm{c}$ is the upstream gas concentration in $\mathrm{mol} / \mathrm{m}^{3}$ :

$$
\mathrm{c}=\frac{\mathrm{P}_{1}}{\mathrm{RT}}
$$

On the downstream side, if pressure variation $\Delta \mathrm{P}$ is due to the diffusion of $\mathrm{N}$ gas moles, then:

$$
\mathrm{N}=\frac{\Delta \mathrm{P}}{\mathrm{RT}} \mathrm{V}_{\mathrm{r}}
$$

During time variation $\Delta \mathrm{t}$, gas molar flowrate $\Delta \Phi$ in $\mathrm{mol} / \mathrm{s}$ is:

$$
\Delta \Phi=\mathrm{N} / \Delta \mathrm{t}
$$

Finally, for steady state unidirectional gas transfer, Fick's law writes $\Delta \Phi=D A \frac{c}{e}$ so that diffusion coefficient $\mathrm{D}\left(\right.$ in $\left.\mathrm{m}^{2} / \mathrm{s}\right)$ is:

$$
\mathrm{D}-\frac{e \mathrm{~V}_{\mathrm{r}}}{\mathrm{AP}_{1}} \frac{\Delta \mathrm{P}}{\Delta t}
$$

Three $\mathrm{P}_{1}$ values are tested with $\mathrm{N}_{2}$, and six $\mathrm{P}_{1}$ values with pure $\mathrm{H}_{2}$. For comparison purposes, a single value $\mathrm{P}_{1}=1.5 \mathrm{MPa}$ is used with pure $\mathrm{Ar}$ or pure $\mathrm{N}_{2}$.

\subsection{Concentration gradient technique}

A classical diffusion test is carried out at atmospheric pressure $\mathrm{P}_{1}=\mathrm{P}_{2}$ with a specific original cell (Fig. 3), regardless of gas nature. Although of rectangular shape, sample surface are $A^{\prime}$ is similar to that in the pressure gradient technique. In this experiment, a mass spectrometer is calibrated for each gas (here, $\mathrm{N}_{2}$ and $\mathrm{H}_{2}$ ) and used to detect and quantify gas particles passing through the polymer membrane. The cell is divided into two parts. The upstream volume is filled with a mixture of $\mathrm{N}_{2} / \mathrm{H}_{2}$ (at 2.5 / 5 or $10 \mathrm{~mol} \% \mathrm{H}_{2}$ ). Diffusing particles are quantified in the downstream volume. It is flown through by a carrier gas $\left(\mathrm{N}_{2}\right)$, which atomic number is sufficiently far from $\mathrm{H}_{2}$ to improve resolution. Because the gas mixture is of low $\mathrm{H}_{2}$ concentration, combined with a low diffusive membrane, a static method has been devised to limit test duration. It consists in isolating the downstream volume from ambient air for 2 to 3 days, and collecting a detectable gas concentration, on the order of $0.1 \%$ (reliable measure with the spectrometer). The measurement is repeated 3 times for reproducibility. 


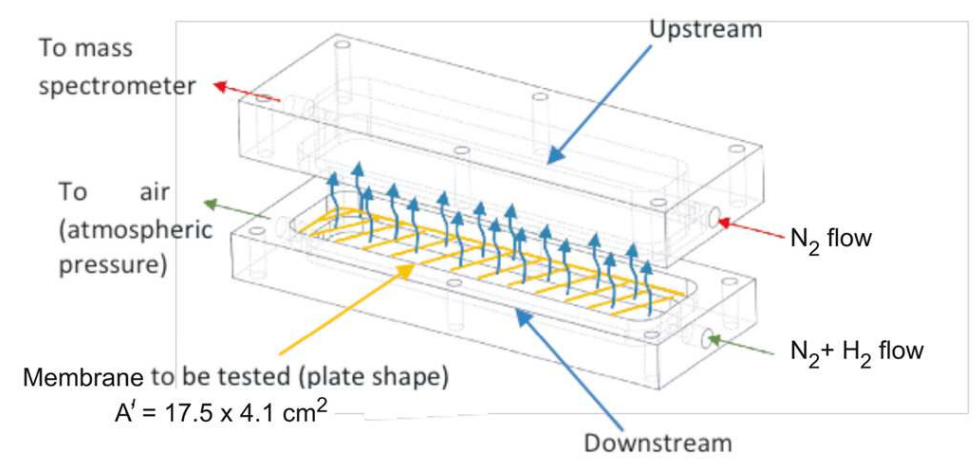

Fig. 3. 3D representation of the diffusion experimental set-up, applying a gas concentration gradient to a HDPE membrane (in dashed yellow).

For a gas with $\mathrm{m} \mathrm{mol} \% \mathrm{H}_{2}$, upstream concentration cup (in $\mathrm{mol} / \mathrm{m}^{3}$ ) is:

$$
\mathbf{c}_{\mathrm{up}}=\mathrm{m} \frac{\mathbf{P}_{1}}{\mathrm{RT}}
$$

where $\mathrm{P}_{1}$ is equal to $10^{5}$ Pascal (atmospheric pressure).

After time $\Delta t$, in the carefully calibrated downstream chamber of volume $V_{a}$, a small downstream concentration (compared with $\mathrm{m}$ ) is measured, equal to $\mathrm{p}$ (mol\%). This corresponds to M diffused moles:

$$
\mathrm{M}=\mathrm{p} \frac{\mathrm{P}_{1}}{\mathrm{RT}} \mathrm{V}_{\mathrm{a}}
$$

To apply Fick's law through the membrane $\left(\Delta \Phi=D A^{\prime} \frac{\varepsilon_{u p}}{e}\right)$, a constant concentration gradient equal to $\left(\mathrm{c}_{\mathrm{up}} / \mathrm{e}\right)$ is assumed $(\mathrm{p}<<\mathrm{m})$. During $\Delta \mathrm{t}$, mean gas flowrate $\Delta \Phi(\mathrm{in} \mathrm{mol} / \mathrm{s})$ is:

So that

$$
\Delta \Phi=\mathrm{M} / \Delta \mathrm{t}
$$

Where $A^{\prime}$ is the membrane surface area.

$$
\mathrm{D}=\frac{e p V_{a}}{m S A^{\prime} \Delta t}
$$

\section{Results and discussion}

Whatever the polymer considered, each permeameter experiment lasts $4 \mathrm{~h}$, whereas the classical diffusion technique requires 2-3 days. Therefore, the permeameter experiment is an accelerated measurement of gas transfer properties through polymer membranes.

\subsection{Gas transfer phenomenon during pressure gradient test}

As shown in Appendix, when gas is applied as a pressure gradient and flows steadily through the polymer membrane, several definitions exist for permeability, either $\mathrm{K}_{\text {app }}$ in the Darcy's sense, as described in Eq. (2) [4-9] or $\mathrm{P}_{\mathrm{e}}$ according to Eq. (A10) [10-16].

In Darcy's sense, i.e. if gas flows by advection through the polymer membrane, gas flowrate $\mathrm{Q}$ scales with $\mathrm{P}_{1}^{2}$ (square of the imposed pressure on the upstream side) (Eq. (2)). This is described through apparent gas permeability $\mathrm{K}_{\text {app }}$. Comparatively, if gas diffuses 
according to Fick's first law, $\mathrm{Q}$ is proportional to pressure $\mathrm{P}_{1}$ (Eqs. (1) and (6)). This is described by permeability coefficient $P_{e}$ in [10-16] or directly by diffusion coefficient $D$ (see Sub-section 2.1). $\mathrm{P}_{\mathrm{e}}$ and $\mathrm{D}$ are directly related (Appendix 1.2, Eq. (A12)).

For HDPE membranes subjected to pure $\mathrm{H}_{2}$ flow, Fig. 4 shows that, at different gas injection levels $\mathrm{P}_{1}$, gas volumetric flowrate $\mathrm{Q}$ is a linear function of $\mathrm{P}_{1}$. This is characteristic of diffusion-driven transport. This observation is identical whatever the gas nature $\left(\mathrm{H}_{2}, \mathrm{H}_{\mathrm{e}}\right.$, Ar or $\left.\mathrm{N}_{2}\right)$, and for both HDPE and epoxy membranes. It is concluded that during pressure gradient test, polymer membranes are mainly subjected to diffusion.

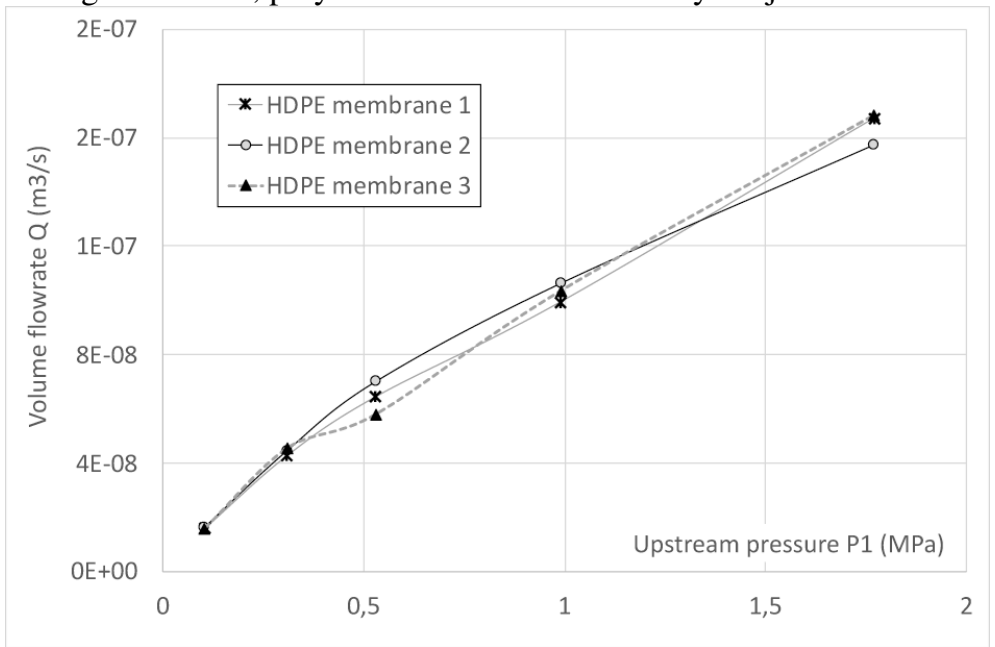

Fig. 4. Under pressure gradient technique, steady-state volume flowrate $\mathrm{Q}=\left(\mathrm{V}_{\mathrm{r}} / \mathrm{P}_{2}\right) *(\Delta \mathrm{P} / \Delta \mathrm{t})$ for membranes n.1, 2, 3 as a function of upstream gas pressure $\mathrm{P}_{1}$. Applied gas is pure $\mathrm{H}_{2}$. Downstream pressure $\mathrm{P}_{2}$ is equal to atmospheric pressure.

In the case of argon flow through HDPE membranes at $\mathrm{P}_{1}=1.5 \mathrm{MPa}$, diffusion coefficient $\mathrm{D}$ is calculated at an average value of $6.5 \times 10-13 \mathrm{~m}^{2} / \mathrm{s}+/-0.3$. This corresponds to $\mathrm{P}_{\mathrm{e}}$ values of $9.8 \times 10^{-16} \mathrm{~m}^{2}$.s.Pa $\mathrm{Pa}^{-1}+/-3.9$. When comparing with values for HDPE from the literature [14] (see also Appendix 1.2), $\mathrm{P}_{\mathrm{e}}$ is significantly lower than for HDPE containing $21 \%$ amorphous matter. Our result is attributed to a greater crystallinity (or to a greater mineral charge content) of the patented HDPE tested in this research.

\subsection{HDPE diffusion properties}

With the permeameter, HDPE diffusion coefficients with $\mathrm{N}_{2}$ (or Ar) and $\mathrm{H}_{2}$ (or $\mathrm{He}$ ) differ by approximately one order of magnitude, indicating a much slower $\mathrm{N}_{2}$ (or Ar) transfer than that of $\mathrm{H}_{2}$ (or He), see Table 1. A greater diffusion coefficient is obtained with Ar when compared to $\mathrm{N}_{2}$, owing to a smaller atom size than $\mathrm{N}_{2}$ molecule. Comparatively, $\mathrm{He}$ and $\mathrm{H}_{2}$ diffusion coefficients are close, as their respective atom or molecule size suggests. This is consistent with results from [2].

Results analyzed as apparent gas permeability $\mathrm{K}_{\mathrm{app}}$ are significantly more dispersed than those analyzed with diffusion. Moreover, $\mathrm{K}_{\text {app }}$ values are very low, ranging between $4.210^{-24}-1.3210^{-22} \mathrm{~m}^{2}$. This is also indicative that the main gas transfer phenomenon is diffusion rather than advection. 
Table 1. Apparent gas permeability $\mathrm{K}_{\mathrm{app}}$ and gas diffusion coefficient $\mathrm{D}$ for HDPE membranes n. 1, 2 and 3 with the pressure gradient technique, with $\mathrm{N}_{2}, \mathrm{Ar}, \mathrm{He}$ or $\mathrm{H}_{2}$.

\begin{tabular}{|c|c|c|c|c|c|}
\hline & $\begin{array}{c}\text { Plate } \\
\mathbf{n}^{\circ}\end{array}$ & $\begin{array}{c}\text { Upstream } \\
\text { pressure } P_{1} \\
\text { (MPa rel.) }\end{array}$ & $\begin{array}{c}\text { Apparent gas } \\
\text { permeability } K_{\text {app }} \\
\left(\mathbf{m}^{2}\right)\end{array}$ & $\begin{array}{c}\text { Diffusion } \\
\text { coefficient D } \\
\left(\mathbf{m}^{2} / \mathbf{s}\right)\end{array}$ & $\begin{array}{c}\begin{array}{c}\text { Average } \mathbf{D}+/- \text { one standard } \\
\text { deviation }\end{array} \\
\left(\mathbf{m}^{2} / \mathbf{s}\right)\end{array}$ \\
\hline \multirow{9}{*}{$\mathbf{N}_{2}$} & \multirow{3}{*}{1} & 0.104 & $3.110^{-23}$ & $310^{-13}$ & \multirow{9}{*}{$\begin{aligned} & 1.310^{-13} \\
&+/-0.710^{-13}\end{aligned}$} \\
\hline & & 0.306 & $8.210^{-24}$ & $1.3210^{-13}$ & \\
\hline & & 0.610 & $6.410^{-24}$ & $1.5410^{-13}$ & \\
\hline & \multirow{3}{*}{2} & 0.120 & $1.510^{-23}$ & $1.410^{-13}$ & \\
\hline & & 0.306 & $6.010^{-24}$ & $0.8910^{-13}$ & \\
\hline & & 0.602 & $4.210^{-24}$ & $1.010^{-13}$ & \\
\hline & \multirow{3}{*}{3} & 0.118 & $8.210^{-24}$ & $0.7710^{-13}$ & \\
\hline & & 0.306 & $6.010^{-24}$ & $0.8910^{-13}$ & \\
\hline & & 0.602 & $4.210^{-24}$ & $1.010^{-13}$ & \\
\hline \multirow{3}{*}{ Ar } & 1 & 1.5 & - & $8.010^{-13}$ & \multirow{3}{*}{$\begin{aligned} & 7.910^{-13} \\
&+/-0.310^{-13}\end{aligned}$} \\
\hline & 2 & 1.5 & - & $7.610^{-13}$ & \\
\hline & 3 & 1.5 & - & $8.110^{-13}$ & \\
\hline \multirow{3}{*}{$\mathbf{H e}$} & 1 & 1.5 & - & $1.310^{-12}$ & \multirow{3}{*}{$\begin{array}{l}1.210^{-12} \\
+/-0.110^{-12}\end{array}$} \\
\hline & 2 & 1.5 & - & $1.210^{-12}$ & \\
\hline & 3 & 1.5 & - & $1.210^{-12}$ & \\
\hline \multirow{18}{*}{$\mathbf{H}_{2}$} & \multirow{6}{*}{1} & 0.104 & $1.2710^{-22}$ & $2.1610^{-12}$ & \multirow{18}{*}{$\begin{array}{c}2.010^{-12} \\
+/-0.810^{-12}\end{array}$} \\
\hline & & 0.113 & $1.110^{-22}$ & $1.910^{-12}$ & \\
\hline & & 0.310 & $6.910^{-23}$ & $210^{-12}$ & \\
\hline & & 0.530 & $4.210^{-23}$ & $1.710^{-12}$ & \\
\hline & & 0.990 & $2.110^{-23}$ & $1.410^{-12}$ & \\
\hline & & 1.770 & $1.210^{-23}$ & $1.3410^{-12}$ & \\
\hline & \multirow{6}{*}{2} & 0.104 & $1.3210^{-22}$ & $2.2410^{-12}$ & \\
\hline & & 0.113 & $1.010^{-22}$ & $1.7510^{-12}$ & \\
\hline & & 0.310 & $7.210^{-23}$ & $2.0510^{-12}$ & \\
\hline & & 0.530 & $4.610^{-23}$ & $1.910^{-12}$ & \\
\hline & & 0.990 & $2.310^{-23}$ & $1.510^{-12}$ & \\
\hline & & 1.770 & $1.1510^{-23}$ & $1.2610^{-12}$ & \\
\hline & \multirow{6}{*}{3} & 0.104 & $1.2710^{-22}$ & $2.2610^{-12}$ & \\
\hline & & 0.113 & $1.110^{-22}$ & $1.8410^{-12}$ & \\
\hline & & 0.310 & $7.310^{-23}$ & $2.110^{-12}$ & \\
\hline & & 0.530 & $3.810^{-23}$ & $1.610^{-12}$ & \\
\hline & & 0.990 & $2.210^{-23}$ & $1.4910^{-12}$ & \\
\hline & & 1.770 & $1.2310^{-23}$ & $1.3510^{-12}$ & \\
\hline
\end{tabular}

With the classical gas concentration technique (Table 2), good agreement is obtained between the average $\mathrm{D}\left(\mathrm{H}_{2}\right)$ value $\left(3.310^{-12} \mathrm{~m}^{2} / \mathrm{s}+/-1.410^{-12}\right)$ and that measured with the permeameter (average $\mathrm{D}\left(\mathrm{H}_{2}\right)=2.010^{-12} \mathrm{~m}^{2} / \mathrm{s}+/-0.7810^{-12}$ ), with less scatter with the latter technique. This is another way to demonstrate that the permeameter test may be interpreted as an accelerated diffusion test, by neglecting convective transport.

Table 2. Gas diffusion coefficient D for HDPE membrane $n$. 4 with the classical diffusion set-up used with a $\mathrm{H}_{2}$ concentration gradient (mixed with varying amounts of $\mathrm{N}_{2}$ ).

\begin{tabular}{|c|c|c|c|c|}
\hline & \multirow{2}{*}{$\begin{array}{c}\text { Plate } \\
\mathbf{n}^{\circ}\end{array}$} & \multirow{2}{*}{$\begin{array}{c}\text { Upstream } \\
\text { concentration } \\
(\mathrm{mol} \%)\end{array}$} & \multirow{2}{*}{$\begin{array}{c}\text { Diffusion } \\
\text { coefficient } \\
\text { D }\left(\mathrm{m}^{2} / \mathbf{s}\right)\end{array}$} & Average D +/- one \\
\hline & & & & standard deviation $\left(\mathrm{m}^{2} / \mathrm{s}\right)$ \\
\hline \multirow{3}{*}{$\mathbf{H}_{2}$} & \multirow{3}{*}{4} & 2.5 & $3.410^{-12}$ & \multirow{3}{*}{$\begin{array}{r}3.310^{-12} \\
+/-1.410^{-12}\end{array}$} \\
\hline & & 5.0 & $1.810^{-12}$ & \\
\hline & & 10.0 & $4.710^{-12}$ & \\
\hline
\end{tabular}




\subsection{Epoxy diffusion properties}

With the accelerated diffusion experiment (using the pressure gradient technique in steady state), results on HDPE are compared to those for epoxy with either argon or helium (Fig. 5). Whereas helium diffusion is quite high and very close for both polymer membranes (with average values of $1.2 \times 10^{-12} \mathrm{~m}^{2} / \mathrm{s}$ for HDPE and $0.8 \times 10^{-12} \mathrm{~m}^{2} / \mathrm{s}$ for epoxy), argon diffuses with more difficulty through epoxy than through HDPE (with average values of $7.9 \times 10-13 \mathrm{~m}^{2} / \mathrm{s}$ for HDPE and $0.3 \times 10^{-13} \mathrm{~m}^{2} / \mathrm{s}$ for epoxy). This means that gas diffusion through epoxy is more sensitive to gas nature, i.e. that epoxy is a more selective polymer to gas diffusion.

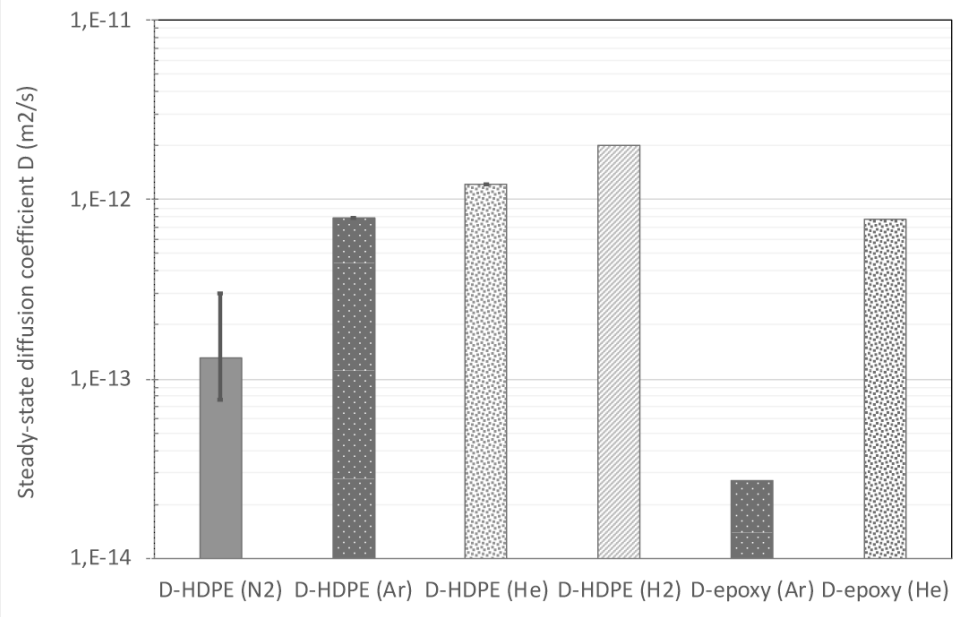

Fig. 5. Average results of diffusion coefficient D for HDPE membranes, compared to epoxy membranes (1 sample only), using the pressure gradient technique.

\section{Conclusion}

This study combines 1) the design of two original experimental devices and 2) the fast reliable measurement of HDPE and epoxy membrane transport properties to $\mathrm{H}_{2}$ gas (and $\mathrm{Ar}, \mathrm{N}_{2}, \mathrm{He}$ ). With both pressure and concentration gradient techniques, Fick's law provides similar diffusion coefficients $\mathrm{D}\left(\mathrm{H}_{2}\right)$ (uniform isotropic medium), at $2.010^{-12} \mathrm{~m}^{2} / \mathrm{s}+/-0.78$ $10^{-12}$ (pressure gradient) or $3.310^{-12} \mathrm{~m} 2 / \mathrm{s}+/-1.410^{-12}$ (concentration gradient). The pressure gradient technique is faster (4h instead of 2-3 days), because higher gas pressure increases $\mathrm{H} 2$ concentration on the sample upstream side.

Gas nature plays a major role, as e.g. $\mathrm{N}_{2}$ gas flowrate is ten times smaller than for $\mathrm{H}_{2}$, under equivalent pressure conditions (average $\left.\mathrm{D}\left(\mathrm{N}_{2}\right)=1.310^{-13}+/-0.6810^{-13}\right)$. Given the very small quantities of gas involved, it is also noted that diffusion through HDPE is almost independent of gas concentration or pressure. This is not the case with epoxy, which diffusion coefficient shows a greater dependency on gas nature. 


\section{References}

1. A. Irankhah, S. M. S. Fattahi, M. Salem, I. J. Hyd. Ene. DOI: 10.1016/j.ijhydgene.2018.07.014. 2018

2. D. W. Van Krevelen., K. te Nijenhuis., Elsevier Science Ed. 1030 p. ISBN 9780080548197. 2009

3. A. Cruz-Aguilar, D. Navarro-Rodriguez, O. Pérez-Camacho, S. Fernandez-Tavizon, C. A. Gallardo-Vega, M. Garcia-Zamora, E. D. Barriga-Castro, M. T. Comm. DOI : 10.1016/j.mtcomm.2018.06.003. 2018

4. A. Abbas, M. Carcasses, J. P. Ollivier, Mater. Struct., 32, 3-8 (1999)

5. J. J. Kollek, Mater. Struct. 22, 225-230 (1989)

6. F. Skoczylas, J.P. Henry, Int. J. Rock Mech. Min. Sci \& Geomech. Abstr. 32 (2), 171179 (1995)

7. C. A. Davy, F. Skoczylas, J. D. Barnichon, P. Lebon, Phys. Chem. Earth. 32 , 667-680 (2007)

8. W. Wang, J. Liu, F. Agostini, C. A. Davy, F. Skoczylas, D. Corvez, Cem. Con. Res. DOI : 10.1016/j.cemconres.2013.09.008. 2014

9. F. Zhang, Z. Duan, F. Skoczylas, J. F. Shao, Eur. J. Environ. Civ. En. DOI: 10.1080/19648189.2015.1110058. 2015.

10. T. V. Naylor, Comprehensive polymers science (Oxford, Pergamon Press, 643-668, 1989)

11. J. Crank, The mathematics of diffusion (Oxford, Oxford University, 1975)

12. P. Neogi, Diffusion in polymers (New York, Marcel Dekker, 173-210, 1996)

13. C. E. Rogers, Engineering design for plastics (ed. E. Baer, New York, Reinhold, 609688, 1964)

14. B. Flaconnèche, J. Martin, M. H. Klopffer, Oil Gas Sci. Technol. 56 (3), 261-278 (2001)

15. M. H. Klopffer, Ph. Berne, E. Espuche, Oil Gas Sci. Technol. 70 (2), 305-315 (2015)

16. M. H. Klopffer, B. Flaconnèche, P. Odru, Plast. Rubber Compos. 36 (5), 184-189 (2007) 


\section{Appendix}

Determination of the pressure profile for the unidirectional transfer of a perfect gas through a material of thickness e.

Let consider a gas present at a pressure difference $\left(\mathrm{P}_{1}-\mathrm{P}_{2}\right)$ (with $\left.\mathrm{P}_{1}>\mathrm{P}_{2}\right)$ between two sides of a porous material of thickness e. Gas is assumed to transfer by permeation, in the Darcy's sense, along a single axis $\mathrm{x}$ (Fig. A1).

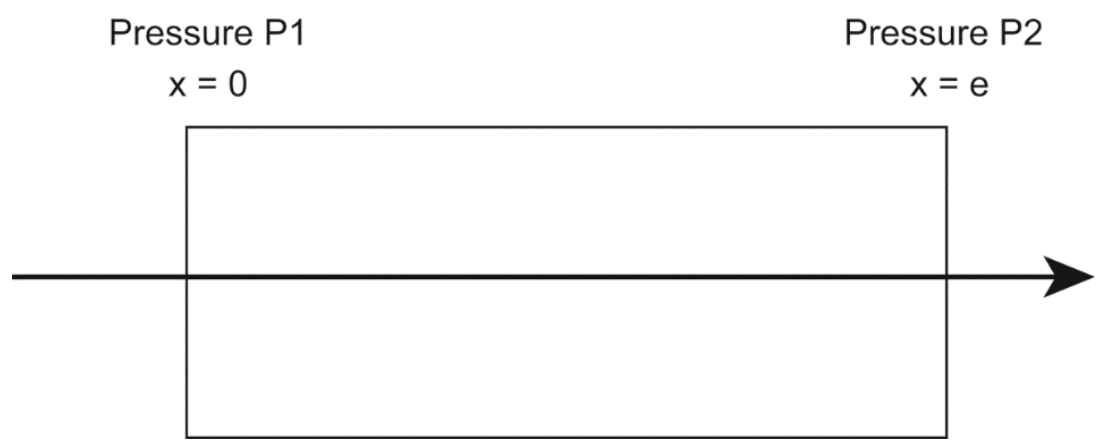

Fig. A1. Representation of the unidirectional gas transferthrough a porous material of thickness e.

Mass conservation and Darcy's law are written as:

$$
\begin{gathered}
\frac{\partial\left(\rho_{f} \phi\right)}{\partial t}+\operatorname{div}\left(\rho_{f} \overrightarrow{q_{f}}\right)=0 \\
\overrightarrow{q_{f}}=-\frac{K}{\mu_{f}} \overrightarrow{\nabla P}
\end{gathered}
$$

where $\rho_{f}$ is fluid density (in $\mathrm{kg} / \mathrm{m}^{3}$ ), $\overrightarrow{q_{f}}$ is gas velocity (in $\mathrm{m} \cdot \mathrm{s}^{-1}$ ), $\phi$ is porosity, $\mu_{f}$ is fluid dynamic viscosity (in Pa.s), $\mathrm{K}$ is permeability in $\mathrm{m}^{2}$, and $\mathrm{P}$ is local pressure. Let add the state equation for gas, assumed perfect:

$$
P=\frac{R T}{M_{f}} \rho_{f}
$$

where $\mathrm{R}$ is the perfect gas constant (equal to $8.31 \mathrm{~J} \cdot \mathrm{mol}^{-1} \cdot \mathrm{K}^{-1}$ ), $\mathrm{T}$ is temperature (in $\mathrm{K}$ ) and Mf is fluid molar mass (in $\mathrm{kg} / \mathrm{mol}$ ). Combining Eqs. A1, A2 and A3 provides diffusivity equation:

$$
\frac{K}{\mu_{f}} \operatorname{div}(P \overrightarrow{\nabla P})=\phi \frac{\partial P}{\partial t}
$$

Under steady state flow, Eq. A4 leads to $\operatorname{div}(P \overrightarrow{\nabla P})=0$, which is integrated for a unidirectional flow along axis $\mathrm{x}$ as:

$$
P=\sqrt{P_{1}^{2}\left(1-\frac{x}{e}\right)+P_{2}^{2} \frac{x}{e}}
$$


This means that the pressure gradient at $\mathrm{x}=\mathrm{e}$ is written as:

$$
\left(\frac{d P}{d x}\right)=-\frac{\left(P_{1}^{2}-P_{2}^{2}\right)}{2 e P_{2}}
$$

Derivation of Darcy's permeability, Fick's diffusion coefficients and solubility

Using Eq. (A6), Darcy's law describing gas velocity $q_{f}\left(\right.$ in $\left.\mathrm{m}_{\mathrm{s}} \mathrm{s}^{-1}\right)$ in the steady state writes:

$$
q_{f}=\frac{K}{\mu_{f}} \frac{\left(P_{1}^{2}-P_{2}^{2}\right)}{2 e P_{2}}
$$

$q_{f \text { is measured experimentally as: }} q_{f}=Q / A$ where Q is volumetric flowrate (in m3.s-1) and sample surface area $\mathrm{A}$ is in $\mathrm{m}^{2}$. Finally, one gets:

$$
\mathrm{Q}=\mathrm{K} \frac{\mathrm{A}\left(\mathrm{P}_{1}^{2}-\mathrm{P}_{2}^{2}\right)}{2 \mu_{f} \mathrm{P}_{2}}
$$

This equation means that gas volumetric flowrate $\mathrm{Q}$ scales with $\mathrm{P}_{1}{ }^{2}$ (square of the imposed pressure on the upstream side).

Comparatively, and also in the steady state, the polymer testing literature [10-16] defines a rate of transfer $F$ (in $\mathrm{m}_{\mathrm{s}} \mathrm{s}^{-1}$ ) in relation to a so-called permeability coefficient $\mathrm{P}_{\mathrm{e}}$ (in $\left.\mathrm{m}^{2} \cdot \mathrm{s}^{-1} \cdot \mathrm{Pa}^{-1}\right)$ by:

$$
F=P_{e} \frac{\left(P_{1}-P_{2}\right)}{e}
$$

In [14], for HDPE membranes of varying crystallinity and temperatures ranging between $40-80^{\circ} \mathrm{C}$, Pe varies between 0.95 and $4.8 \times 10^{-17} \mathrm{~m}^{2} / \mathrm{s} / \mathrm{Pa}$ for He diffusion $\left(0.76-2.06 \times 10^{-17}\right.$ $\mathrm{m}^{2} / \mathrm{s} / \mathrm{Pa}$ for Ar diffusion and 0.5-1.6 $\times 10^{-17} \mathrm{~m}^{2} / \mathrm{s} / \mathrm{Pa}$ for $\mathrm{N}_{2}$ diffusion). No significant difference in $\mathrm{Pe}$ is observed depending on gas nature. Temperature and crystallinity are more influential on Pe than gas nature.

Moreover, rate of transfer $\mathrm{F}$ is identical to $q_{f}$ in (Eq. A7), so that with $\mathrm{F}=Q /{ }_{A}$, one gets:

$$
Q=P_{e} \frac{A\left(P_{1}-P_{2}\right)}{e}
$$

Gas volumetric flowrate scales with $\mathrm{P}_{1}$, imposed pressure on the upstream side. In this research, it is shown experimentally on HDPE membranes that Q scales rather with $\mathrm{P}_{1}$ than $\mathrm{P}_{1}^{2}$, so that permeability in the Darcy's sense, as given by Eq. (A8), is not adequate to describe the actual gas transfer phenomenon.

As shown in Eq. (A10), the so-called permeability coefficient $\mathrm{P}_{\mathrm{e}}$ corresponds to a fluid transfer proportional to $\mathrm{P}_{1}$, which is typical of gas transfer by diffusion. By using Eqs. 1, 3, 4 and 5 (see main text), with the assumption of a diffusional transfer, volumetric flowrate writes:

$$
\mathrm{Q}=\frac{V_{r}}{P_{2}} \frac{\Delta P}{\Delta t}=\frac{D A P_{1}}{e P_{2}}
$$


This equation shows that volumetric flowrate $\mathrm{Q}$ depends on upstream pressure $\mathrm{P}_{1}$ with a proportionality coefficient D (i.e. diffusion coefficient from Fick's first law). Combining Eqs. (A10) and (A11) provides a relationship between Pe and D as:

$$
P_{e}=D \frac{P_{1}}{P_{2}\left(P_{1}-P_{2}\right)}
$$

Eq. (A12) means that these two parameters have different dimension, but both can be deduced from steady-state diffusion measurements. 